\title{
Local Anesthetics Lidocaine and Bupivacaine as Pre-emptive Analgesia in Lumbar Region Degenerative Spinal Surgery Patients with Posterior Approach
}

\author{
Andhika Yudistira*(i), Agustinus Budhi Prasetio (D), Lasa Dhakka Siahaan (D), Muhammad Alwy Sugiarto(D) \\ Department of Orthopedics and Traumatology, Faculty of Medicine, Universitas Brawijaya,RSUD Dr. Saiful Anwar, Malang, \\ East Java, Indonesia
}

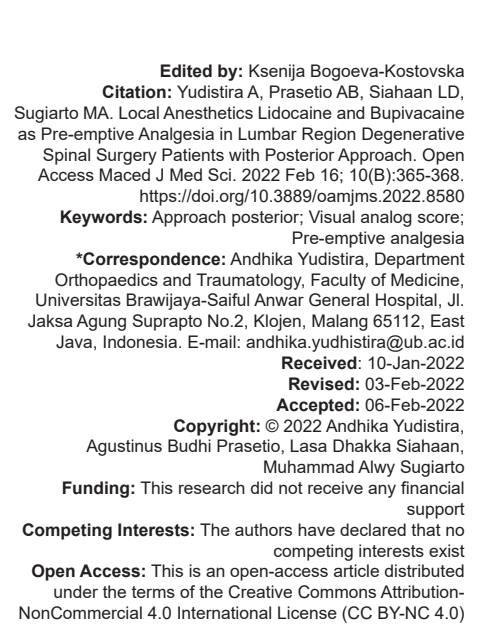

\begin{abstract}
BACKGROUND: Pain management with pre-emptive analgesia is a pain management strategy to reduce acute post-operative pain.

AIM: This research aimed to determine the effectiveness of local anesthetics Lidocaine and Bupivacaine to reduce acute pain after the lumbar spine degenerative surgery using a posterior approach.

METHODS: This study was observational research with a prospective cohort and was carried out in 2021 at RSUD Dr. Saiful Anwar Malang with a sample of 12 in each test. The samples obtained were in accordance with the inclusion and exclusion criteria.

RESULTS: This assessment used was the Visual Analogue Score (VAS); an instrument for measuring the degree of pain experienced by patients with a value range of $0-10$. Bupivacaine group achieved a lower VAS score more than lidocaine and the control group with VAS score 2; however, in another group, mostly was dominated by $3-5$ VAS score during fullow-up periode.

CONCLUSION: This research showed that pre-emptive analgesia administration using local infiltration of Lidocaine or Bupivacaine before incision in degenerative surgery of the lumbar spine with a posterior approach had a significant effect on the scale of acute post-operative pain. Bupivacaine reduces the post-operative pain scale more effectively than Lidocaine up to $48 \mathrm{~h}$ postoperatively.
\end{abstract}

\section{Introduction}

The most common spinal column surgery procedures performed by orthopedic specialists use a posterior approach [1]. A posterior approach is the most common and easiest approach to perform in spinal surgery. This approach has fewer complications than the other approaches. This approach allows access to several levels for several types of operating procedures. In fact, no approach has better functionality than the posterior midline approach in spinal surgery [2].

In reality, spinal surgery is a major surgical procedure, which often causes extreme pain after surgery [3]. Acute pain is an unpleasant emotional and mental sensation associated with vegetative cues, physiological responses, and behavioral changes [4]. In addition, spinal surgery with a posterior approach will provide trauma to the tissue along the incision area accompanied by local inflammation, which will activate nociceptive receptors as part of the acute post-operative pain experienced by the patient. The activation of these nociceptive receptors will be continued by afferent nerve fibers and trigger central sensitization so that in the future; it can cause chronic pain felt by the patient. Therefore, the administration of local anesthesia in the incision area of patients with degenerative spinal surgery with a posterior approach is expected to inhibit the activation of nociceptive receptors and prevent central sensitization so that the patient's post-operative pain response can be reduced [5].

Post-operative acute pain management aims to increase patient comfort, patient satisfaction, early patient mobilization, reduce the risk of pulmonary and cardiac complications, reduce the risk of deep vein thrombosis, better healing process, and reduce the cost of care for post-operative patients. The importance of reducing the post-operative pain rate will reduce the nociceptive response [1]. One of several options of pain management is pre-emptive analgesia. Pre-emptive analgesia can be given through General Anesthesia or Local Anesthesia. Providing pre-emptive analgesia can intervene in both central and peripheral pain pathways, depending on the modality decided by the team of doctors. Some methods that can be done are infiltration with local anesthetics, 
nerve blocks, epidural blocks, subarachnoid blocks, intravenous analgesia, and NSAIDs [6].

Several orthopedic surgeons have carried out the practice of giving pre-emptive analgesia in various sub-fields of science, particularly spine surgery. However, until now, conclusive data regarding the effectiveness of local anesthetic infiltration as preemptive analgesia to reduce acute post-operative pain has not been published. Very few publications have been found on the effectiveness of local anesthetic infiltration as pre-emptive analgesia after spinal surgery. The aim of this study was to determine the effectiveness of local anesthetics Lidocaine and Bupivacaine in reducing acute pain after degenerative surgery of the lumbar spine using a posterior approach. This article has followed the STROBE checklist and guidelines.

\section{Methods}

A prospective cohort study was conducted in RSUD Dr. Saiful Anwar, Malang, Indonesia. This research sample was patients who underwent degenerative surgery of the lumbar spine with an approach whose inclusion and exclusion criteria had been determined. Pre-emptive analgesia with local infiltration anesthesia by giving infiltration anesthesia using Lidocaine (maximum dose $4 \mathrm{mg} / \mathrm{kgBW}$ ), with or without epinephrine, or Bupivacaine (maximum dose $1.5 \mathrm{mg} / \mathrm{kgBW}$ ). It was performed by an orthopedic spine specialist 5 min before incision. All bone surgery patients with a posterior approach received sedation and General Anesthesia procedures, then positioned prone. During the operation, the patient will receive the same analgesic during the operation.

The research sample were patients who were going to undergo degenerative surgery of the lumbar region of the spine with the posterior approach at dr. Saiful Anwar Malang RSUD. The research sample was obtained based on inclusion and exclusion criteria. The inclusion criteria were male and female patients aged 20-90 years with degenerative spine problems in the lumbar segment. The exclusion criteria were patients who undergo degenerative surgery of the lumbar spine with hemostasis or blood clotting disorders. These patients underwent spinal surgery through two approaches (example: Posterior and anterior), patients who were allodynia or hyperalgesia, and patients that have sensory, myelopathy, neurologic deficits upper motor neuron impairment. The sample size was carried out using the method according to the Lemeshow formula and obtained minimal samples used for each group of 12 patients. Therefore, the samples obtained were 36 patients with 12 male patients and 24 female patients depending on inclusion and exclusion criteria. The samples were divided into three groups: the control group (without pre-emptive analgesia), the Lidocaine group, and the Bupivacaine group.
In this research, the assessment model used was the Visual Analogue Score (VAS), an instrument for measuring the degree of pain experienced by patients with a range of values from 0 to 10 . By translating the value $0=$ no pain, $10=$ very severe pain. The patient will be shown the range of values and told the value of the degree of pain he has experienced (0-1-2-3-4-5-6-7-8-9-10). Moreover, the patient will give the score at the $6^{\text {th }}, 12^{\text {th }}, 24^{\text {th }}$, and $48^{\text {th }} \mathrm{h}$.

Observation and assessment of post-operative pain with VAS score were carried out by double-blinded observational method, where the observer and the patient did not know the type of pre-emptive analgesia given by the operator to each sample. The assessment of the pain scale was carried out by the observer with witnesses from the family and the nurse.

\section{Data analysis}

The post-operative pain results with VAS at 6 , $12,24,48 \mathrm{~h}$ were recorded in profile tables. The data analysis used was unpaired ordinal nonparametric analytic analysis $>2$ groups (control, lidocaine group, and bupivacaine group), with the Kruskal Wallis test and continued with the Mann Whitney test. The significant difference is when $p<0.05$.

\section{Results}

\section{Control group (without local anesthesia)}

The following table was the results of observations from the control group, namely the sample group who underwent degenerative surgery of the lumbar spine through the posterior approach. There were 12 patients observed with VAS at $6 \mathrm{~h}-12 \mathrm{~h}-24 \mathrm{~h}-48 \mathrm{~h}$ after surgery (Table 1).

Table 1: VAS score outcome from control group

\begin{tabular}{llll}
\hline No & Diagnosis & Action & VAS (6: 12: 24: 48) \\
\hline 1 & Spondylolisthesis V.Lumbal 4-5 & PSD & $4: 4: 4: 4$ \\
2 & Canal Stenosis V. Lumbal 1-2 & D & $4: 4: 4: 4$ \\
3 & Canal Stenosis V.Lumbal 5-S1 & D & $4: 4: 4: 4$ \\
4 & HNP V.Lumbal 4-5 & PSD & $4: 4: 5: 5$ \\
5 & Canal Stenosis V.Lumbal 1-2 & D & $4: 4: 4: 4$ \\
6 & HNP V.Lumbal 4-5 & D & $4: 4: 4: 4$ \\
7 & Canal Stenosis V.Lumbal 4-5 & D & $4: 4: 5: 5$ \\
8 & Lumbal Canal Stenosis V.L3-4 L4-5 & PSD & $4: 4: 5: 5$ \\
9 & Lumbal Canal Stenosis V.L4-5 & D & $4: 4: 4: 4$ \\
10 & Canal Stenosis V.Lumbal 3-5 & PSD & $4: 4: 4: 4$ \\
11 & HNP V.Lumbal 3-5 & D & $4: 4: 4: 4$ \\
12 & Spondylolisthesis V.Lumbal 4-5 & PSD & $4: 4: 5: 5$ \\
\hline PS: Posterior stabilization, D: Decompression, PSD: Posterior stabilization and decompression, \\
VAS: Visual Analogue Score.
\end{tabular}

The following were the results of observation of each group that included 12 patients who underwent degenerative surgery of the lumbar region of the spine through the posterior approach.

The control group serves as a comparison to find out the differences that may appear between the experimental group and the control group. VAS score in the control group had a higher value than in the lidocaine 
or bupivacaine groups. In this group, the VAS score in the first $6 \mathrm{~h}$ was mostly 4 and tended to be constant in the majority of subject's study. However, in 4 subject's study, the VAS score increased to 5 at 24-48 h during follow-up.

\section{Lidocaine group}

Before incision, a local infiltration was administered using $1 \%$ lidocaine with a maximum dose of $4 \mathrm{mg} / \mathrm{kg} \mathrm{BW}$. Post-operative pain scale assessment was carried out at $6 \mathrm{~h}-12 \mathrm{~h}-24 \mathrm{~h}-48 \mathrm{~h}$ (Table 2).

Table 2: VAS score outcome from lidocain group

\begin{tabular}{llll}
\hline No & Diagnosis & Action & VAS (6: 12: 24: 48) \\
\hline 1 & HNP VL4-5, VL5-S1 & D & $3: 3: 3: 3$ \\
2 & Lumbal Canal Stenosis VL 3-4, 4-5 & PSD & $4: 4: 5: 5$ \\
3 & Lumbal Canal Stenosis VL 2-3, VL 3-4, VL 4-5 & PSD & $3: 3: 3: 3$ \\
4 & Lumbal Canal Stenosis VL 3-4, VL 4-5 & PSD & $3: 3: 3: 3$ \\
5 & Lumbal Canal Stenosis VLII - S1 & PSD & $3: 3: 3: 3$ \\
6 & Lumbal Canal Setnosis VL 4-5 & PSD & $3: 3: 3: 3$ \\
7 & Lumbal Canal Stenosis VL 1-2 & PSD & $3: 3: 3: 3$ \\
8 & Lumbal Canal Stenosis VL3-5 & PSD & $3: 3: 3: 3$ \\
9 & Lumbal Canal Stenosis VL 4-S1 $1: 3: 3$ \\
10 & Lumbal Canal stenosis VL 4-5 & PSD & $3: 3: 3: 3$ \\
11 & Lumbal Canal stenosis VL 2 - S1 & D & $3: 3: 3: 3$ \\
12 & Lumbal Canal Stenosis VL 2-3 & PSD & $3: 3: 3: 3$ \\
\hline PS: Posterior stabilization, D: Decompression, PSD: Posterior stabilization and decompression,
\end{tabular}

VAS: Visual Analogue Score.

VAS outcome in the lidocaine group at $6 \mathrm{~h}$ after surgery majority score was three that has achieved on nine patients, and only 1 patient reported with VAS score of four. The VAS score in the lidocaine group was inclined constantly from the first $6 \mathrm{~h}$ until $48 \mathrm{~h}$ during follow-up periods. However, only 1 case was reported there was a VAS score of 4 in the first $6 \mathrm{~h}$ and increased to VAS score 5 in the next $24 \mathrm{~h}$ during follow-up.

\section{Bupivacaine group}

A local infiltration was administered using $0.5 \%$ Bupivacaine with a maximum dose of $2 \mathrm{mg} / \mathrm{kg} \mathrm{BW}$. Post-operative pain scale assessment was carried out at $6 \mathrm{~h}-12 \mathrm{~h}-24 \mathrm{~h}-48 \mathrm{~h}$ (Table 3).

Table 3: VAS score outcome from bupivacain group

\begin{tabular}{llll}
\hline No & Diagnosis & Action & VAS $(6: 12: 24: 48)$ \\
\hline 1 & Lumbal Canal Stenosis VL III-S1 & PSD & $2: 2: 2: 2$ \\
2 & Lumbal Canal Stenosis VL5-S1 & PSD & $2: 2: 2: 2$ \\
3 & Lumbal Canal Stenosis VL4-5-S1 & D & $2: 2: 2: 2$ \\
4 & Lumbal Canal Stenosis VL 4-5- & PSD & $2: 2: 3: 3$ \\
& S1+spondylolisthesis VL5-S1 & & \\
5 & HNP VL4-5, VL5-S1 & D & $2: 2: 2: 2$ \\
6 & HNP VL5 - S1 & D & $2: 2: 2: 2$ \\
7 & Lumbal Canal Stenosis VL5-S1 & D & $3: 3: 2: 2$ \\
8 & Lumbal Canal Stenosis VL1-2 & PSD & $2: 2: 2: 2$ \\
9 & HNP VL4-S1 & PSD & $2: 2: 2: 2$ \\
10 & HNP VL1-5 & PSD & $3: 3: 2: 2$ \\
11 & Lumbal Canal Stenosis VL1-2 & D & $2: 2: 2: 2$ \\
12 & HNP VL 4-S1 & D & $3: 3: 2: 2$ \\
\hline PS: Posterior stabilization, D: Decompression, PSD: Posterior stabilization and decompression, VAS: Visual \\
Analog Score.
\end{tabular}

The bupivacaine group had the same incline tendency as the lidocaine group, which seemed constant from the first $6 \mathrm{~h}$ to the next $48 \mathrm{~h}$. However, the bupivacaine group achieved a lower VAS score than lidocaine and the control group. In this group, the highest score was 3 on the $61^{\text {st }} \mathrm{h}$ during follow-up. However, in 2 cases, the VAS score decreased from 3 to 2 after 24 h later.

A hypothesis test was conducted using a oneway ANOVA to find the relationship of research with an error rate of $5 \%$ or a $95 \%$ level of confidence. However, before using parametric statistics, the first test of normality and data homogeneity is required. The normality test using Shapiro-Wilk showed that do not significance value $(p)$ or not show normal distribution and homogenity test do not homogen disribution. Consequently, we used the Kruskal Wallis test for determining differences in the effect between treatments groups. Significant can be seen in the Kruskal-Wallis and test from Table 4.

Table 4: Kruskall-wallis test

\begin{tabular}{lll}
\hline Time & Chi-square & p-value \\
\hline $6 \mathrm{~h}$ & 28.728 & 0.000 \\
$12 \mathrm{~h}$ & 28.728 & 0.000 \\
$24 \mathrm{~h}$ & 31.110 & 0.000 \\
$48 \mathrm{~h}$ & 31.110 & 0.000 \\
\hline
\end{tabular}

\section{Mann-whitney test}

The comparison between each group after the Kruskal Wallis test was carried out, followed by using the Mann-Whitney test. The results of the Mann-Whitney test have a difference between groups is shown if it has a $p<0.05$. The test results at each predetermined time were as follows Table 5

\section{Table 5: Mann-Whitney test result}

\begin{tabular}{llll}
\hline Time & Group comparison & & p-value \\
\hline $6 \mathrm{~h}$ & Control & Lidocaine 1\% & 0.0000 \\
& Control & Bupivacaine 0.5\% & 0.0000 \\
& Lidocaine 1\% & Bupivacaine 0.5\% & 0.0028 \\
$12 \mathrm{~h}$ & Control & Lidocaine 1\% & 0.0000 \\
& Control & Bupivacaine 0.5\% & 0.0000 \\
& Lidocaine 1\% & Bupivacaine 0.5\% & 0.0028 \\
$24 \mathrm{~h}$ & Control & Lidocaine 1\% & 0.0000 \\
& Control & Bupivacaine 0.5\% & 0.0000 \\
& Lidocaine 1\% & Bupivacaine 0.5\% & 0.0003 \\
$48 \mathrm{~h}$ & Cntrol & Lidocaine 1\% & 0.0000 \\
& Control & Bupivacaine 0.5\% & 0.0000 \\
& Lidocaine 1\% & Bupivacaine 0.5\% & 0.0003 \\
\hline
\end{tabular}

Based on the Table 4, it can be seen that the control group had a significant difference with the Lidocaine $1 \%$ and Bupivacaine $0.5 \%$ groups. Likewise, the Lidocaine $1 \%$ and groups and Bupivacaine $0.5 \%$ have a significant difference.

After significant spine surgery procedures, intolerable morbidity arises as a result of post-operative pain. Various surgical techniques and pharmacological therapy have been carried out to reduce post-operative spine pain. This study aims to compare the effectiveness of lidocaine versus bupivacaine in patients with degenerative spine disorder. Therefore, we compared our result with a previous study.

\section{Discussion}

In our study, we found that post-operative surgery had serious pain as consideration to control pain. In this case, Post-operative pain treatment may seem like an interesting method that, in theory, it has the potential to enhance early post-operative pain control to reduce the requirement for opioids, thereby minimalize side effects of opioids or long-term of NSID [7]. 
From the results of our study, it was found that the administration of bupivacaine achieved vas score relatively lower more than others group with vas score mostly 2 during follow-up and almost constant in 24-48 h post operation than the control group and the lidocaine group, which means the bupivacaine higher effectiveness than the other. These results were in parallel studies by Jabeen et al. (2020) that the reduction of the postoperative pain scale in the Lidocaine and bupivacaine sample groups is in accordance with the study of the research group with localized bupivacaine infiltration in the area around the incision can significantly reduce acute post-operative pain [6]. These results also reflect those of palazon et al. (1992) who also found that $2.5 \%$ bupivacaine or ropivacaine infiltration of the surgical site was equally efficient in treating pain following lumbar disk laminectomy [8]. Hereafter, combination of corticosteroid with bipuvacaine was reported that have more statistically significant more than bupivacain only [9].

From the same number of research samples between the lidocaine group and the bupivacaine group, it can be seen that Bupivacaine reduces the post-operative pain scale more effectively than Lidocaine, up to $48 \mathrm{~h}$ postoperatively. This result is probably due to the longacting nature of Bupivacaine which has a longer half-life so that it blocks the transmission of pain due to repetitive tissue trauma during surgery for a longer duration. This is probably due to the long acting nature of Bupivacaine which has a longer half-life so that it blocks the transmission of pain due to repetitive tissue trauma during surgery for longer [4]. Contrary to the previous statement, effectiveness and duration of action of Lidocaine, only can last up to $10 \mathrm{~h}$ in combination with epinephrine and $5 \mathrm{~h}$ without epinephrine [10]. whereas for Bupivacaine it lasts for $15 \mathrm{~h}$ and the duration of analgesia can last up to $30 \mathrm{~h}$. The administration of epinephrine combination can extend even the duration of anesthesia and analgesia [11]. Hereafter, Bupivacaine administration is believed to be able to shorten the length of stay in the hospital [12].

However, the administration of doses and types of intravenous analgesia perioperatively is also a point that cannot be uniform in each sample due to the need for pre and operative analgesia, which is different in each sample. Postoperatively, patients received analgesia using an intravenous ketorolac injection of $30 \mathrm{mg}$ every $8 \mathrm{~h}$. Post-operative factors that may cause pain response in patients should also be considered. Further experimental research is needed to accurately describe the onset of acute pain that occurs in post-operative patients and long-term observation to assess the ultimate goal of the study is to prevent the onset of chronic pain in patients and also the effective dose and safety of bupivacaine drugs needed to explore for further research.

From this study, we can take conclusion that administration of pre-emptive analgesia using local infiltration of Lidocaine or Bupivacaine before incision in degenerative surgery of the lumbar spine with a posterior approach significantly affected the post-operative acute pain scale. However, Bupivacaine lowered the post-operative pain scale more effectively than Lidocaine up to $48 \mathrm{~h}$ postoperatively.

\section{References}

1. Sekar C, Rajasekaran S, Kannan R, Reddy S, Shetty TA, Pithwa YK. Preemptive analgesia for postoperative pain relief in lumbosacral spine surgeries: A randomized controlled trial. Spine J. 2004;4(3):261-4. https://doi.org/10.1016/j.spinee.2003.11.009 PMid:15125846

2. Emel E, Abdallah A, Özer AF. Posterior approach to the lumbar and lumbosacral junction. In: Surgical Anatomy: Principles of Spinal Surgery. İntertıp Yayınevi; 2016. p. 337-49.

3. Kim SI, Ha KY, Oh IS. Preemptive multimodal analgesia for postoperative pain management after lumbar fusion surgery: A randomized controlled trial. Eur Spine J. 2016;25(5):1614-9. https://doi.org/10.1007/s00586-015-4216-3 PMid:26324284

4. Svehla J, Beran T. Lecba pooperacni bolesti. Anesteziol Neodkladna Pece. 2000;11:95.

5. Rivkin A, Rivkin MA. Perioperative nonopioid agents for pain control in spinal surgery. Am J Health Pharm. 2014;71(21):1845-57. https://doi.org/10.2146/ajhp130688 PMid:25320134

6. Jabeen M, Zafar F, Tabassam S, Alam F, Sohail M. Role of local infiltration of injection bupivacaine in reducing early postoperative pain. J Univ Med Dent Coll. 2020;11(1):1-8. https:// doi.org/10.37723/jumdc.v11i1.306

7. Kjærgaard M, Møiniche S, Olsen KS. Wound infiltration with local anesthetics for post-operative pain relief in lumbar spine surgery: Asystematic review.ActaAnaesthesiol Scand.2012;56(3):282-90. https://doi.org/10.1111/j.1399-6576.2011.02629.x PMid:22260370

8. Hernández-Palazón J, Serrano JA, López SB, Molero EM Infiltration of the surgical wound with local anesthetic for postoperative analgesia in patients operated on for lumbar disc herniation. Comparative study of ropivacaine and bupivacaine. Rev Esp Anestesiol Reanim. 2001;48(1):17-20.

PMid:11234601

9. Mirzai H, Tekin I, Alincak H. Perioperative use of corticosteroid and bupivacaine combination in lumbar disc surgery: A randomized controlled trial. Spine (Phila Pa 1976). 2002;27(4):343-6. https:// doi.org/10.1097/00007632-200202150-00003 PMid:11840097

10. Thomson CJ, Lalonde DH. Randomized double-blind comparison of duration of anesthesia among three commonly used agents in digital nerve block. Plast Reconstr Surg. 2006;118(2):429-32. https://doi.org/10.1097/01.prs.0000227632.43606.12 PMid:16874214

11. Calder K, Chung B, O'Brien C, Lalonde DH. Bupivacaine digita blocks: How long is the pain relief and temperature elevation? Plast Reconstr Surg. 2013;131(5):1098-104. https://doi. org/10.1097/PRS.0b013e3182865dbb PMid:23629091

12. Glasser RS, Knego RS, Delashaw JB, Fessler RG. The perioperative use of corticosteroids and bupivacaine in the management of lumbar disc disease. J Neurosurg. 1993;78(3):383-7. https://doi.org/10.3171/jns.1993.78.3.0383 PMid:8433138 